\title{
Laparoscopy-Assisted Billroth I Gastrectomy for Ectopic Pancreas in the Prepyloric Region
}

\author{
Yueh-Tsung Lee ${ }^{a, d, e}$ Ho Lin ${ }^{d, f}$ Jen-Chang Guo ${ }^{b}$ \\ Sheng-Lei Yan ${ }^{c, e}$ Hsiang-Jen Hou ${ }^{a, e}$ Yih-Shyong Lai ${ }^{b}$ \\ Yi-Hsiang Liu ${ }^{b}$ Hurng-Sheng $\mathrm{Wu}^{\mathrm{a}}$ e Min-Ho Hwang ${ }^{\mathrm{a}, \mathrm{e}}$ \\ Departments of ${ }^{\mathrm{a}}$ Surgery, ${ }^{\mathrm{b}}$ Pathology and ${ }^{\mathrm{c}}$ Gastroenterology, Chang-Bing Show \\ Chwan Memorial Hospital, Lugang, ${ }^{d}$ Department of Life Sciences, National \\ Chung-Hsing University, Taichung, and ${ }^{\mathrm{e}}$ Asian IRCAD (Research Institute against \\ Cancer of the Digestive Tract, Asian Institute of TeleSurgery in Taiwan), \\ Lugang, Taiwan; 'Department of Urology, University of Texas Southwestern \\ Medical Center, Dallas, Tex., USA
}

\section{Key Words}

Laparoscopy-assisted Billroth I gastrectomy · Ectopic pancreas · Prepyloric region

\begin{abstract}
Ectopic pancreatic tissue is an uncommon developmental anomaly. The condition mostly occurs in the gastrointestinal tract and is usually asymptomatic. It rarely causes symptoms of inflammation, bleeding and perforation, and has potential for malignant change. Though it is an uncommon condition, cases of ectopic pancreas have been reported worldwide. Preoperative diagnosis of ectopic pancreas is challenging because of its nonspecific symptoms and signs. Owing to the revolution of minimally invasive surgery, submucosal tumors of the stomach can be resected by laparoscopic techniques. We have earlier reported on a case of ectopic pancreas in the stomach treated by robotics-assisted laparoscopic wedge resection. Herein, we report a case of ectopic pancreas in the prepyloric region of the stomach. A 44-year-old female presented with a two-week history of epigastralgia with radiation to the back. She received endoscopy check-up which disclosed a mass in the stomach. By endoscopic findings, a submucosal lesion in the prepyloric region with umbilical folding on the mucosa was identified. The umbilical folding on the mucosa hint the orifice of the duct of ectopic pancreas into the gastric mucosa suggestive of ectopic pancreas. Contrast-enhanced abdominal computed tomography showed a $5 \mathrm{~cm}$ cystic mass with heterogeneous content. To sum it up, the patient was diagnosed as ectopic pancreas in the stomach. She underwent laparoscopy-assisted antrectomy with Billroth I anastomosis (excision of the antrum and prepyloric region with reconstruction of gastrointestinal continuity by gastroduodenostomy) and had an uneventful hospitalization course. The histopathology of the resected tumor demonstrated ectopic pancreatic tissue in the gastric
\end{abstract}


wall. To the best of our knowledge, excision of gastric ectopic pancreas using laparoscopyassisted antrectomy with Billroth I anastomosis has never been reported in the literature.

\section{Introduction}

Ectopic pancreas is defined as abnormally situated pancreatic tissue with its own ductal and vascular systems and without anatomical contiguity with normal pancreas $[1,2]$. However, the situation seldom induces symptomatic complaints. Therefore, preoperative diagnosis of ectopic pancreas is very difficult. Occasionally it is an incidental laparotomy or imaging finding. Most patients with ectopic pancreas are asymptomatic, and if present, symptoms are nonspecific and depended on the anatomic location [1-8]. Most of the reported cases are located in the stomach or duodenum $[1,2]$. The other cases were reported in the lower gastrointestinal tract [1-5], retroperitoneum [9], biliary system [10] or intrathoracic region [11]. Complete resection of ectopic pancreatic tissue to eliminate the symptoms is the surgical principle $[12,13]$. For lesions in the digestive tract, the surgeon should consider anatomic and physiologic aspects. The final diagnosis is made according to the histopathological evidence of ectopic pancreatic tissue. We report here a successful case of laparoscopy-assisted antrectomy with Billroth I anastomosis for a protruding gastric submucosal tumor with ectopic pancreas in a 44-year-old female.

\section{Case Report}

A 44-year-old female presented with acute episodes of severe epigastric pain with radiation to the back during the past 2 weeks before admission. Her past history was notable for hypertension and a previous cesarean section 12 years before. She denied any history of blunt abdominal trauma, blood vomiting, tarry stool passage or weight loss. Her vital signs revealed a body temperature of $36.7^{\circ} \mathrm{C}$, a blood pressure of $123 / 81 \mathrm{~mm} \mathrm{Hg}$, a heart rate of 69 beats/min and a respiratory rate of $18 / \mathrm{min}$. Gastroscopy at another institution revealed a submucosal mass in the gastric antrum with umbilical folding suggestive of the possibility of ectopic pancreas (fig. 1 ).

On physical examination there was no anemia or jaundice. No abdominal mass was palpated and bowel sounds were normal without bruit on auscultation. Laboratory data included a hemoglobin of $14.0 \mathrm{~g} / \mathrm{dl}$ (normal 12-16), a hematocrit of 40.9\% (normal 37-47) and a white blood cell count of 5,200/ $\mathrm{mm}^{3}$ (normal 4,500-10,000). Serum blood urea nitrogen was $15 \mathrm{mg} / \mathrm{dl}$ (normal 820), creatinine $0.7 \mathrm{mg} / \mathrm{dl}$ (normal 0.7-1.5), total bilirubin $0.4 \mathrm{mg} / \mathrm{dl}$ (normal $0.2-1.2$ ), glutamate oxaloacetate transaminase $16 \mathrm{IU} / \mathrm{l}$ (normal 8-38), glutamate pyruvate transaminase $25 \mathrm{U} / \mathrm{l}$ (normal 4-14), amylase $57 \mathrm{U} / \mathrm{l}$ (normal 43-116) and lipase $30 \mathrm{U} / \mathrm{l}$ (normal 13-60). The tumor markers were carcinoembryonic antigen $0.92 \mathrm{ng} / \mathrm{ml}$ (normal <5) and carbohydrate antigen 19-9 9.32 U/ml (normal $<37$ ). Chest radiograph and electrocardiography were unremarkable. Contrast-enhanced computed tomography (CT) of the abdomen revealed a $5 \mathrm{~cm}$ submucosal mass with cystic contents and a thickened wall located in the gastric antrum (fig. 2). To summarize the history and clinical examinations, the patient was diagnosed as having a submucosal tumor of stomach, suspected ectopic pancreas.

The patient underwent laparoscopy-assisted antrectomy. At operation, the video port was set by an $11 \mathrm{~mm}$ incision at the umbilical region and pneumoperitoneum was created (Hasson's technique). The other three working ports were set as one $12 \mathrm{~mm}$ channel in left midclavicular plane and two $5 \mathrm{~mm}$ channels in right midclavicular line and right anterior axillary line. The mass was located in the antrum and occupied the prepyloric region (fig. 3 ). The gastrocolic ligament and the lesser omentum were divided by the energy-based cutting device (Ligasure scalpel). The stomach and duodenum were resected by the endoscopic gastrointestinal anastomotic device (GIA linear cutters). The specimen 
including the mass and the gastric antrum was resected completely (fig 4 ). Reconstruction of gastrointestinal continuity was created by handsewn Billroth I anastomosis (gastroduodenostomy) via a minilaparotomy just upon the surgical field. The excised specimen showed a submucosal mass of stomach with umbilical folding on the mucosa ( $\underline{\text { fig. } 5}$ ) and the mass consisted of a well-defined cyst filled with clear fluid (fig. 6). Intraoperative histological frozen section of the submucosal tumor confirmed the benign nature of the mass. Histopathological assessment of the resected specimen showed a picture of ectopic pancreatic tissue in the gastric submucosa with cystic dilatation of the ducts (fig. 7), which was lined by columnar epithelium. The ectopic pancreatic tissue was separated by fibrogranulation tissue (ig. 8). The patient was discharged 9 days after surgery following an uneventful recovery.

\section{Discussion}

Ectopic pancreatic tissue is an uncommon developmental anomaly and mostly occurs in the gastrointestinal tract [1-5, 14] and rarely in the mediastinum [11], the gallbladder [10] or the retroperitoneum [9]. This condition is usually asymptomatic and rarely complicated by pancreatitis [4], gastrointestinal tract bleeding $[3,6]$, perforation [5] or malignant transformation [1, 7, 8], based on anatomical location [1]. Although serum amylase and lipase were normal, our patient presented with severe epigastralgia with radiation to the back suggestive of acute inflammation due to pancreatic duct occlusion with the evidence of cystic change on CT and the surgical specimen [15]. Preoperative diagnosis for ectopic pancreas is difficult even though there are some specific endoscopic signs and endoscopic ultrasound with fine needle aspiration is recommended [1]. The endoscopic findings of our patient demonstrated the presence of umbilical folding on the mucosa of the mass which made us alert for the diagnosis.

Limited gastrectomy for benign lesions in the stomach is a safe and feasible surgical procedure, though endoscopic mucosal resection is an alternative $[12,16]$. Harold et al. [13] reported 4 cases of ectopic pancreas in the stomach who underwent transgastric laparoscopic resection. Furthermore, we have reported a successful case of robotic-assisted laparoscopic wedge resection for ectopic pancreas in a 14-year-old girl [2]. Laparoscopic excision with or without intraoperative histology confirmation has been suggested for ectopic pancreas in the stomach [13,17]. In our case, the submucosal tumor occupied the prepyloric region and postoperative stricture might occur after wedge resection of the submucosal tumor. Endoscopic mucosal resection was not suitable for our patient either because there is a $10 \%$ chance of subserosal invasion of the gastric lesion [1]. As compared with conventional open gastrectomy, laparoscopy-assisted Billroth I gastrectomy is a less invasive surgical technique with less surgical trauma, less impaired nutrition, less pain, rapid recovery of gastrointestinal function, shorter hospital stay, and without decrease in operative curability [18]. Laparoscopic wedge resection of gastric benign lesion with the handsewn method is a valid treatment for selected gastroduodenal tumors in terms of feasibility, safety and cost [19]. We performed the handsewn technique after laparoscopic antrectomy via a minilaparotomy just upon the surgical field not only to facilitate suture security, but also to remove the specimen without manipulating the tumor.

In summary, laparoscopy-assisted Billroth I gastrectomy is safe and feasible for larger cystic tumors, such as ectopic pancreas of the stomach in the case presented. 


\section{Disclosure Statement}

No competing financial interests exist.

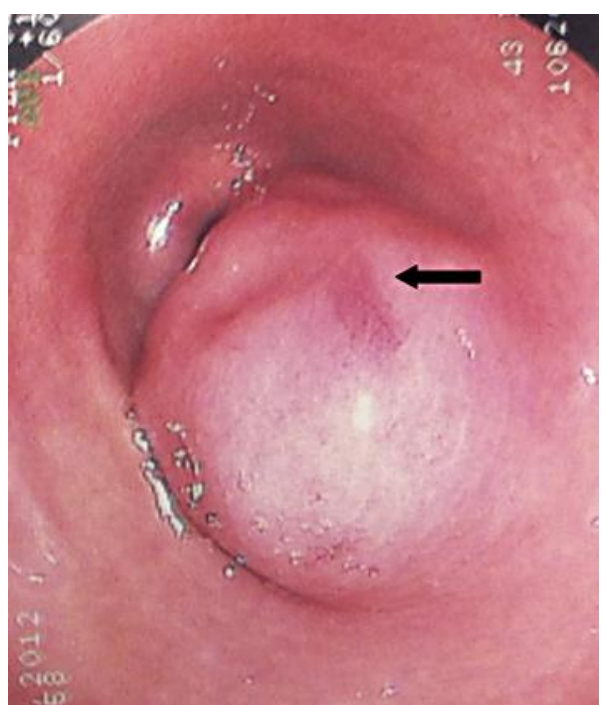

Fig. 1. A submucosal mass protruded into the lumen of the antrum of the stomach. The tumor was $5 \mathrm{~cm}$ in diameter, with umbilical folding on the mucosa (arrow). Usually ectopic pancreas in the stomach presents an orifice for the secretory duct from the pancreatic tissue which causes the appearance of umbilical folding on gastroscopic findings.

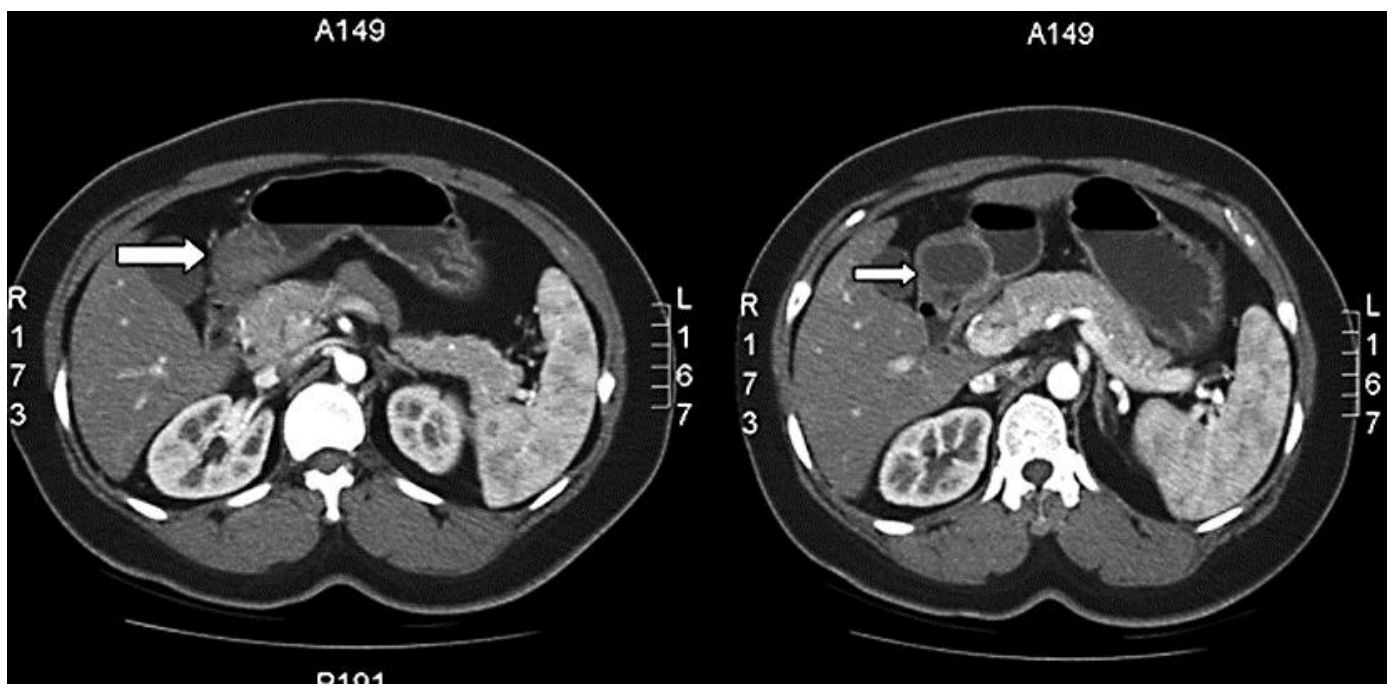

Fig. 2. Contrast-enhanced abdominal CT revealed the mass containing mixed solid (left) and cystic content (right) (arrows). The cystic part in the solid tumor was considered as mixed fluid and soft tissue in the tumor. The pancreatic juice from the ectopic pancreas comprised cystic content. 


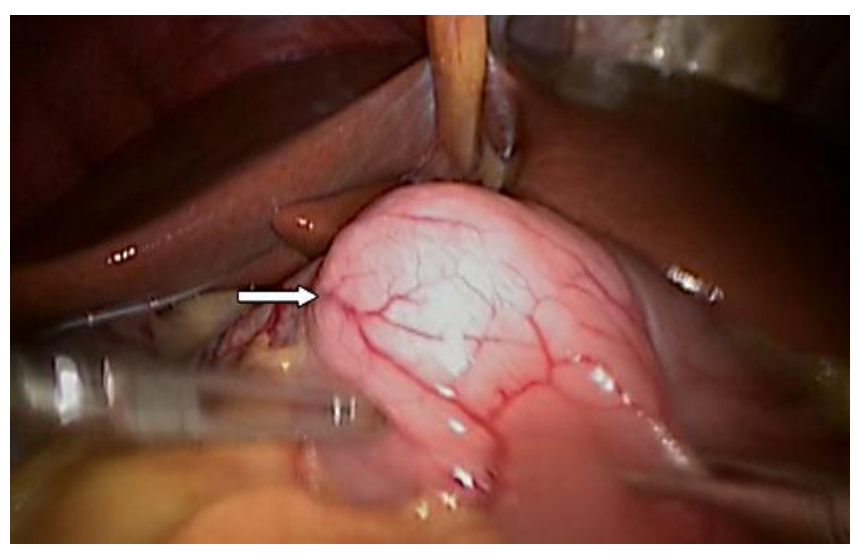

Fig. 3. At laparoscopic surgery, the mass could be identified and grasped by the instrument in the lower portion of the stomach. The location of the tumor was just before the duodenum, the so-called prepyloric region.

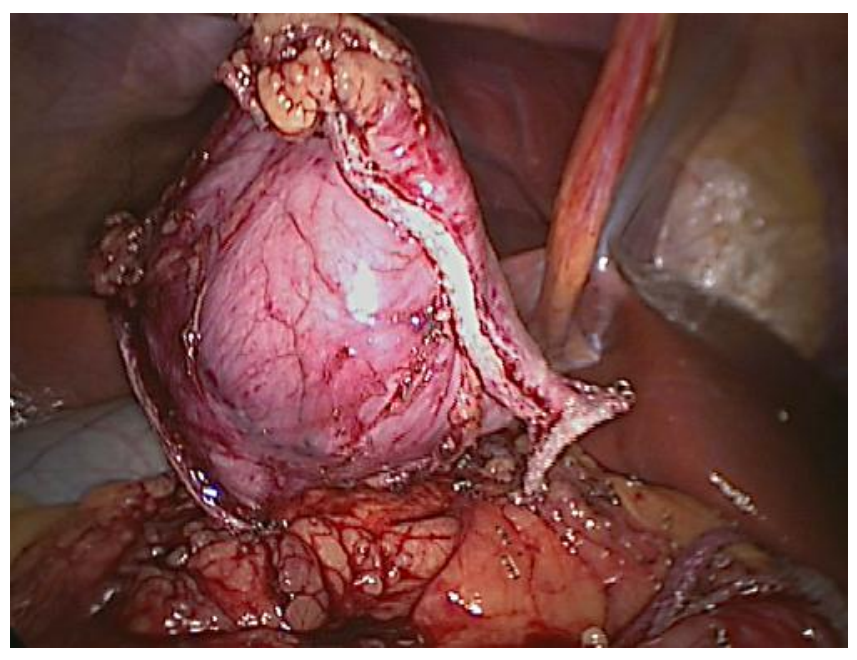

Fig. 4. The antrum and prepyloric region of the stomach including the tumor was excised completely (en bloc resection) by laparoscopic procedure. 


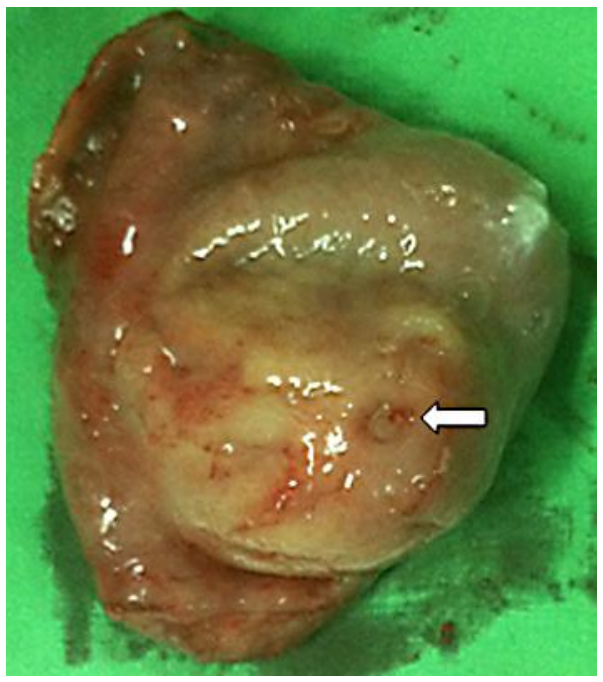

Fig. 5. The resected specimen was incised and a small oval pit on the mucosa of the stomach could be identified which was the opening of the secretory duct of the ectopic pancreas (arrow). The picture was mentioned as umbilical folding, an endoscopic finding of ectopic pancreas in the stomach.

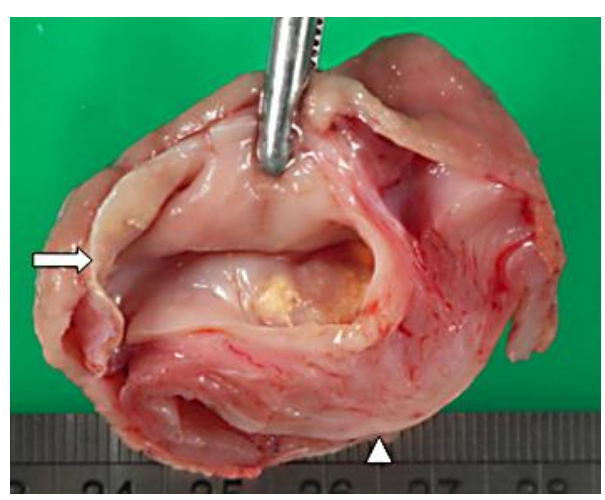

Fig. 6. A wall-off cystic lesion was identified (arrow). The specimen was fixed in formalin (solution containing $10 \%$ formaldehyde) for $16 \mathrm{~h}$. The arrowhead indicates the mucosa of the stomach. 


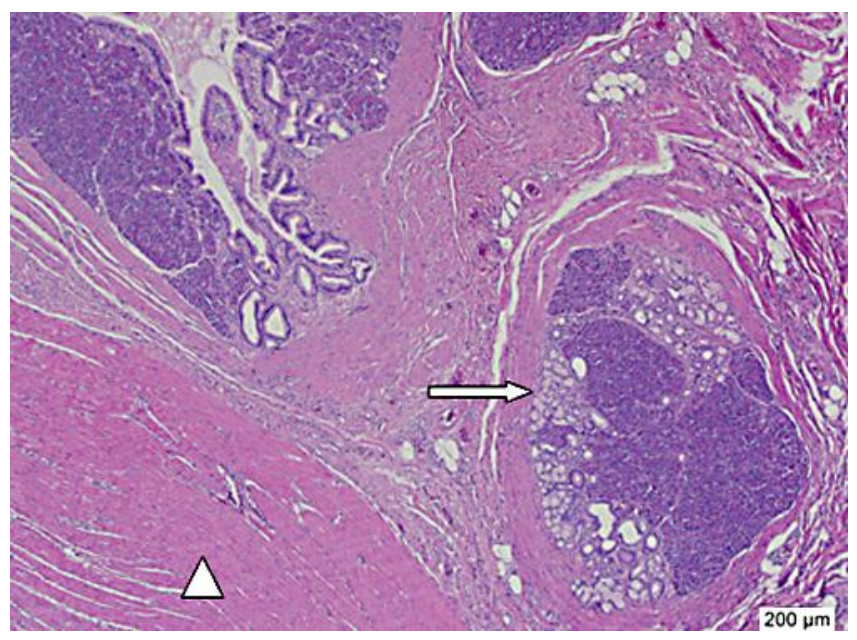

Fig. 7. Microscopically, the formalin-embedded paraffin slide was stained by hematoxylin and eosin reagent (H\&E stain). H\&E stain is a popular staining method in pathology and histology. The nucleus of the cells appeared purple by the hematoxylin staining. The cytoplasm of the cells showed pink color after eosin staining. The picture was amplified 40 times. The pancreatic acini (arrow) consisted of many pink cells with purple nucleus (pancreatic cells) separated by fibrous tissue (arrowhead).

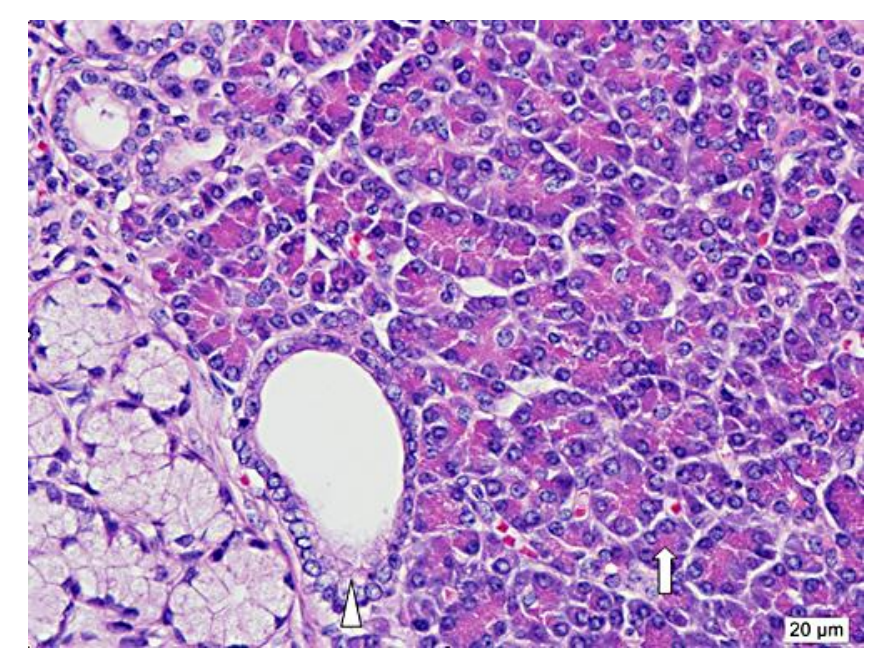

Fig. 8. H\&E staining and 200 $\times$ amplification showed that the pancreatic acini (arrow) consisted of the cells of the ectopic pancreas and that the interlobular duct (arrowhead) was lined by columnar epithelium. 


\section{References}

1 Christodoulidis G, Zacharoulis D, Barbanis S, Katsogridakis E, Hatzitheofilou K: Heterotopic pancreas in the stomach: a case report and literature review. World J Gastroenterol 2007;13:6098-6100.

-2 Hsu SD, Wu HS, Kuo CL, Lee YT: Robotic-assisted laparoscopic resection of ectopic pancreas in the posterior wall of gastric high body: case report and review of the literature. World J Gastroenterol 2005;11:7694-7696.

-3 Yang JF, Sun LM, Wang XF, Dai N: Massive gastrointestinal bleeding from Meckel diverticulum with ectopic pancreatic tissue. Chin Med J (Engl) 2011;124:631-633.

-4 Wong JC, Robinson C, Jones EC, Harris A, Zwirewich C, Wakefield R, Simons RK, Yoshida EM: Recurrent ectopic pancreatitis of the jejunum and mesentery over a 30-year period. Hepatobiliary Pancreat Dis Int 2011;10:218-220

5 Volchok J, Massimi T, Wilkins S, Curletti E: Duodenal diverticulum: case report of a perforated extraluminal diverticulum containing ectopic pancreatic tissue. Arch Surg 2009;144:188-190.

-6 Ah-Soune P, Vitton V, Subtil C, Meunier-Carpentier S, Bonmardion R, Desjeux A, Barthet M, Grimaud JC: Ectopic pancreas: an exceptional cause of lower intestinal bleeding with hemorrhagic shock (in French). Gastroenterol Clin Biol 2008;32:202-204.

-7 Bini R, Voghera P, Tapparo A, Nunziata R, Demarchi A, Capocefalo M, Leli R: Malignant transformation of ectopic pancreatic cells in the duodenal wall. World J Gastroenterol 2010;16:1293-1295.

8 Cardenas CM, Dominguez I, Campuzano M, Bezaury P, Iniguez-Rodriguez M, Gamboa-Dominguez A, Uscanga LF: Malignant insulinoma arising from intrasplenic heterotopic pancreas. JOP 2009;10: 321-323.

-9 Lin LH, Ko SF, Huang CC, Ng SH, Lin JW, Sheen-Chen SM: Retroperitoneal ectopic pancreas: imaging findings. Br J Radiol 2009;82:e253-e255.

10 González Callejas C, González Crespo F, Zurita Saavedra M, Cabrera Aguirre MA, García Martos JB: Ectopic pancreas in the gallbladder. Cir Esp 2012, Epub ahead of print.

11 Szabados S, Lenard L, Tornoczky T, Varady E, Verzar Z: Ectopic pancreas tissue appearing in a mediastinal cyst. J Cardiothorac Surg 2012;7:22.

12 Palanivelu C, Rangarajan M, Parthasarathi R, Senthilkumar R: Laparoscopic resection for benign tumors of the stomach. JSLS 2007;11:81-86.

13 Harold KL, Sturdevant M, Matthews BD, Mishra G, Heniford BT: Ectopic pancreatic tissue presenting as submucosal gastric mass. J Laparoendosc Adv Surg Tech A 2002;12:333-338.

14 Moen J, Mack E: Small-bowel obstruction caused by heterotopic pancreas in an adult. Am Surg 1989;55:503-504.

15 Barbe L, Levy P, Bougaran J, Just J, Mal F, Ruszniewski P, Gayet B: Cystic and mucinous lesion in an antral ectopic pancreas (in French). Gastroenterol Clin Biol 1998;22:824-826.

16 Ryu DY, Kim GH, Park do Y, Lee BE, Cheong JH, Kim DU, Woo HY, Heo J, Song GA: Endoscopic removal of gastric ectopic pancreas: an initial experience with endoscopic submucosal dissection. World ] Gastroenterol 2010;16:4589-4593.

-17 Galvez-Valdovinos R, Mendoza-Rodriguez A, Coronado-Perez JH, Santillan EM, Funes-Rodriguez F: Laparoscopic treatment of heterotopic pancreas in the prepyloric region. J Minim Access Surg 2006;2: 224-226.

18 Adachi Y, Shiraishi N, Shiromizu A, Bandoh T, Aramaki M, Kitano S: Laparoscopy-assisted Billroth I gastrectomy compared with conventional open gastrectomy. Arch Surg 2000;135:806-810.

19 Lee JH, Han HS, Kim YW, Min SK, Lee HK: Laparoscopic wedge resection with handsewn closure for gastroduodenal tumors. J Laparoendosc Adv Surg Tech A 2003;13:349-353. 